\title{
Expression of CD10 in Malignant Müllerian Mixed Tumors and Adenosarcomas: An Immunohistochemical Study
}

\author{
Yoshiki Mikami, M.D., Sakae Hata, C.T., Takako Kiyokawa, M.D., Toshiaki Manabe, M.D. \\ Department of Pathology, Kawasaki Medical School Hospital (YM, SH, TM), Kurashiki, Okayama; and \\ Department of Pathology, Jikei University School of Medicine (TK), Minato-ku, Tokyo, Japan
}

CD10 has been demonstrated to be positive in endometrial stromal sarcoma (ESS) and thus is useful in establishing the diagnosis, but its expression in malignant müllerian mixed tumor (MMMT) and müllerian adenosarcoma remains to be clarified. In this study, 12 cases of MMMT (9 uterine, 2 tubal, and 1 metastatic), 6 cases of müllerian adenosarcoma (three corporeal, two cervical, and one tubal), and 7 cases of primary uterine sarcomas had their tissues examined immunohistochemically for expression of CD10, desmin, myoglobin, $\alpha$-smooth muscle actin (SMA), and cytokeratin. Of the primary uterine sarcomas, two were primary rhabdomyosarcomas (one cervical and one corporeal), two were ESSs, two were high-grade leiomyosarcomas, and one was a high-grade endometrial sarcoma. Sarcomatous components in all cases of MMMT/and müllerian adenosarcoma, as well as all uterine sarcomas, were positive for $\mathrm{CD10}$, showing moderate to marked staining intensity with varying distribution except in one MMMT, which showed weak and very focal staining. In four MMMTs, three adenosarcomas, and one rhabdomyosarcoma, myoglobinand/or desmin-positive rhabdomyoblastic cells were positive for CD10. The immunoreactivity for CD10 showed the same distribution for $\alpha$-SMA and myoglobin in three and two MMMTs, respectively. In five cases of MMMT, carcinomatous components were focally positive for $\mathrm{CD10}$, and in two cases small populations of round or short spindle cells in sarcomatous components were positive for CD10, $\alpha$-SMA, and cytokeratin (CAM5.2). These results indicate that CD10 expression is not restricted to ESS

Copyright (C) 2001 by The United States and Canadian Academy of Pathology, Inc.

VOL. 15, NO. 9, P. 923, 2001 Printed in the U.S.A.

Date of acceptance: May 10, 2002.

Address reprint requests to: Yoshiki Mikami, M.D., Department of Pathol ogy, Kawasaki Medical School Hospital, 577 Matsushima, Kurashiki, Okayama 701-0192, Japan; e-mail: mika@med.kawasaki-m.ac.jp; fax: 81-86-462-1199.

DOI: $10.1097 / 01 . M P .0000026058 .33869 . D B$ but can be positive in MMMT and müllerian adenosarcoma as well as in a variety of uterine tumors including high-grade leiomyosarcoma and rhabdomyosarcoma. CD10 expression might be one of the characteristics of müllerian system-derived neoplastic mesenchymal cells.

KEY WORDS: Adenosarcoma, CD10, Endometrial stromal sarcoma, Immunohistochemistry, Malignant müllerian mixed tumor.

Mod Pathol 2001;15(9):923-930

CD10 or the common acute lymphoblastic lymphoma antigen (CALLA), a cell surface-neutral endopeptidase (NEP or EC 3.4.24.11) degrading various bioactive peptides, has been used as a diagnostic tool for precursor B-cell and T-cell acute lymphoblastic leukemia $(1,2)$, as well as Burkitt lymphoma (3) and follicular lymphoma (4). Recent studies have demonstrated that CD10 is expressed in a variety of nonhematopoietic tumors, including renal cell carcinoma (5-8), transitional cell carcinoma (8), hepatocellular carcinoma $(9,10)$, gastric and colonic adenocarcinoma (11), prostatic adenocarcinoma (8), rhabdomyosarcomas (8), pancreatic adenocarcinomas (8), solid-pseudopapillary tumor of the pancreas (12), clear cell sarcoma of the kidney (13), glioma $(14,15)$, mediastinal germ cell tumors (16), schwannomas (8), malignant melanomas $(8,17)$, dermatofibroma (17), and dermatofibrosarcoma (17). In addition, CD10 is expressed on endometrial stromal cells $(18,19)$ and thus has been considered useful in making a diagnosis of endometrial stromal sarcoma (ESS; 8, 20-23), which should be distinguished from cellular leiomyoma or leiomyosarcoma. However, CD10 expression in malignant müllerian mixed tumors (MMMTs) and müllerian adenosarcomas has remained to be clarified. Both of these tumors, which are considered to possess müllerian system-derived mesenchymal components, could pose potential diagnostic pitfalls, particularly when limited tissue sampling without epithelial components occurs. In this 
study, we examined MMMTs, adenosarcomas, lowgrade ESSs, high-grade uterine leiomyosarcomas, primary uterine rhabdomyosarcomas, and high-grade endometrial sarcoma to demonstrate the utility and pitfall of CD10 paraffin immunohistochemistry, as well as to provide a better understanding of the phenotypic characteristics of müllerian-derived neoplastic mesenchymal cells.

\section{MATERIALS AND METHODS}

Twelve cases of MMMT (9 uterine, 2 tubal, and 1 metastatic), 6 müllerian adenosarcoma (three corporeal, two cervical, and one tubal), and 7 cases of uterine sarcoma, were retrieved from the files of Kawasaki Medical School Hospital and Jikei University School of Medicine and from consultation files of two of the authors (Y.M. and T.K.). Of the uterine sarcomas, there were two low-grade ESSs, two highgrade leiomyosarcomas, two primary rhabdomyosarcomas (one cervical and one uterine), and one high-grade endometrial sarcoma. All hematoxylin and eosin (H\&E)-stained slides were reviewed for confirmation of the diagnoses, and representative blocks were selected and submitted to immunohistochemistry. The antibodies, vendor sources, and working dilutions are listed in Table 1. Sections (4 $\mu \mathrm{m}$ thick) were cut from paraffin blocks of formalin-fixed tissues and were deparaffinized in xylene and rehydrated in graded alcohols. Immunohistochemical studies were performed using a streptavidin-biotin peroxidase complex method with standard protocols (DAKO, Glostrup, Denmark) for CD10, which was incubated with sections after treatment using a microwave antigen retrieval technique with $10 \mathrm{~mm}$ citrate buffer, $\mathrm{pH}$ 6.0, at high temperature for 5 minutes. Slides were stained with 3,3'-diaminobenzidine as chromogen. For other antibodies, the Envision system (DAKO) was employed without antigen retrieval. The immunostaining results were evaluated in semiquantitative fashion. The distribution of positive cells was expressed as focal $(<10 \%)$, intermediate $(10-50 \%)$, or extensive $(>50 \%)$.

\section{RESULTS}

The sarcomatous components in all cases of MMMT (Figs. 1-4), as well as müllerian adenosar- coma (Fig. 5) and primary rhabdomyosarcoma, were positive for CD10, showing moderate to marked staining intensity with intermediate to extensive distribution, except in one MMMT that showed only focal staining (Table 2). Two lowgrade ESSs were diffusely positive with moderate to strong intensity, whereas high-grade endometrial sarcoma showed moderate intensity and intermediate distribution. In general, spindle and ovoid cells in MMMTs and adenosarcomas were positive regardless of the degree of cytologic atypia, showing a distinct cytoplasmic staining pattern (Fig. 2). In four MMMTs (Fig. 3), three adenosarcomas, and one rhabdomyosarcoma, myoglobin and/or desmin-positive rhabdomyoblastic cells with abundant eosinophilic and filamentous cytoplasm were positive for CD10. The immunoreactivity for CD10 showed a similar distribution for $\alpha$-SMA and myoglobin in three and two MMMTs, respectively, but cells negative for $\alpha$-SMA and myoglobin were also positive for CD10 in some areas. Chondroid and osteosarcomatous components were negative for CD10. In seven cases of MMMT, carcinomatous components, portions of serous or endometrioid adenocarcinoma, and areas showing squamous differentiation and some poorly differentiated solid carcinoma were focally positive for CD10 with cytoplasmic and/or membranous staining patterns (Fig. 4). Differentiation of carcinomatous components was not correlated with CD10 immunoreactivity. In two cases, small populations of round or short spindle cells in sarcomatous components were positive for $\mathrm{CD} 10$ and CAM5.2 and $\alpha$-SMA. In all cases of müllerian adenosarcomas, hypercellular areas consisting of CD10-positive neoplastic spindle cells with strong staining intensity were accentuated in a concentric fashion around the neoplastic glands or cystic spaces (Fig. 5). Of note, in two high-grade leiomyosarcomas, neoplastic cells with pleomorphic nuclei and abundant eosinophilic cytoplasm showed strong and extensive cytoplasmic staining for CD10 (Fig. 6). Normal endometrial stroma that was evaluated as an internal control was diffusely positive for CD10, whereas myometrium was negative for CD10.

\section{DISCUSSION}

Distinction between low-grade ESS and cellular leiomyoma or low-grade leiomyosarcoma can be a

TABLE 1. Antibodies Used in Immunohistochemical Studies

\begin{tabular}{lllll}
\hline \multicolumn{1}{c}{ Antigen } & Clone & Dilution & Antigen Retrieval & Source \\
\hline CD10 & $56 C 6$ & $1: 20$ & Microwave & Novocastra Laboratories (Newcastle-upon-Tyne, UK) \\
Desmin & D33 & $1: 100$ & No antigen retrieval & DAKO (Glostrup, Denmark) \\
Myoglobin & Polyclonal & $1: 3750$ & No antigen retrieval & DAKO \\
$\alpha$-Smooth muscle actin & 1A4 & $1: 50$ & No antigen retrieval & Immunon (Pittsburgh, PA) \\
Cytokeratin & CAM5.2 & $1: 1$ & No antigen retrieval & Becton Dickinson (San Jose, CA) \\
\hline
\end{tabular}



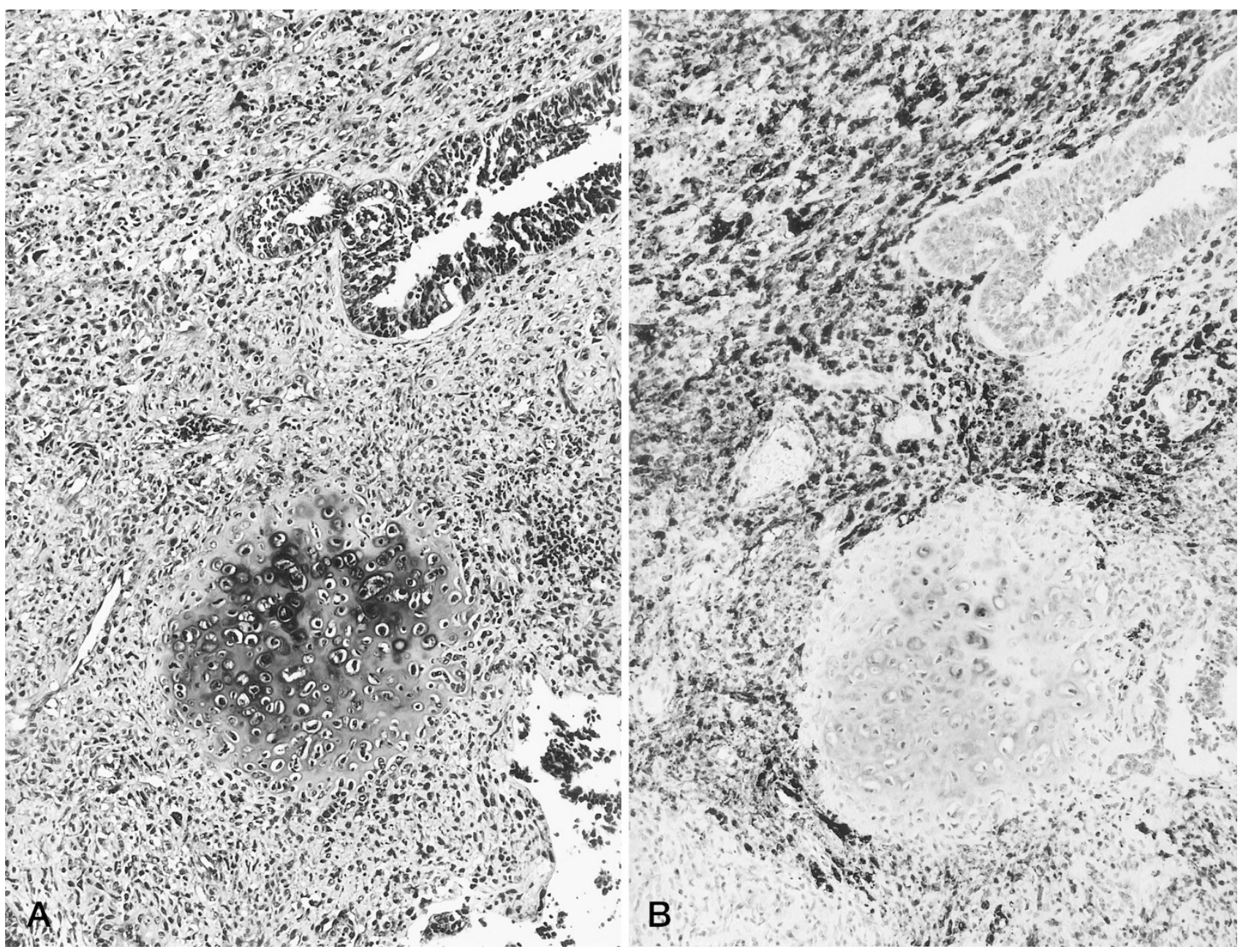

FIGURE 1. Malignant müllerian mixed tümor, consisting of a mixture of carcinomatous añd sarcomatous components with an island of cartilage (A). Immunohistochemistry for CD10, showing diffuse and strong staining of sarcomatous components (B).

problem in the practice of surgical pathology. A constellation of features, that is, resemblance to proliferative-phase endometrial stroma, characterized by closely packed small to medium-sized uniform cells with spindle-shaped or plump ovoid nuclei and numerous small vessels mimicking the spiral arteries and by infiltrative growth in the myometrium, have been considered to be diagnostic. However, occasional smooth muscle differentiation in ESS as represented by expression of $\alpha$-SMA and/or desmin (24-26) may lead to an erroneous interpretation of the results of immunohistochemistry. h-Caldesmon is considered to be a specific smooth muscle marker that is positive in welldifferentiated smooth muscle cells and negative even in desmin- and/or $\alpha$-SMA-positive ESS and thus is considered to be useful in distinguishing smooth muscle tumor from ESS $(27,28)$. Therefore, currently a panel employing a combination of CD10 and h-caldesmon seems contributory in making the distinction between ESS and smooth muscle tumor.

The current study disclosed that MMMTs and adenosarcomas showed distinct cytoplasmic stain- ing for CD10. Recently, four studies have addressed the issue of the utility of CD10 for the diagnosis of ESS, but there has been insufficient information on CD10 expression in MMMTs and adenosarcomas (20-23). Only one case of uterine MMMT in the series examined by McCluggage et al. had endometrial stromal components positive for CD10, showing focal and weak immunoreactivity (22). In 11 (92\%) of 12 cases of MMMTs and all six (100\%) cases of adenosarcoma in our series, sarcomatous components were positive for CD10 with moderate to strong staining intensity and intermediate to extensive distribution. These results are considered significant in contrast to a variety of mesenchymal tumors hitherto examined. Chu and Arber (8) demonstrated that rhabdomyosarcoma most frequently expressed CD10 with a positive rate of $60 \%(3 / 5)$, which was followed by liposarcoma (50\%), schwannoma (45\%), epithelioid sarcoma (28\%), and leiomyosarcoma (6\%). These observations indicate that CD10 expression in the sarcomatous component of MMMTs and adenosarcomas is more than coincidental. 


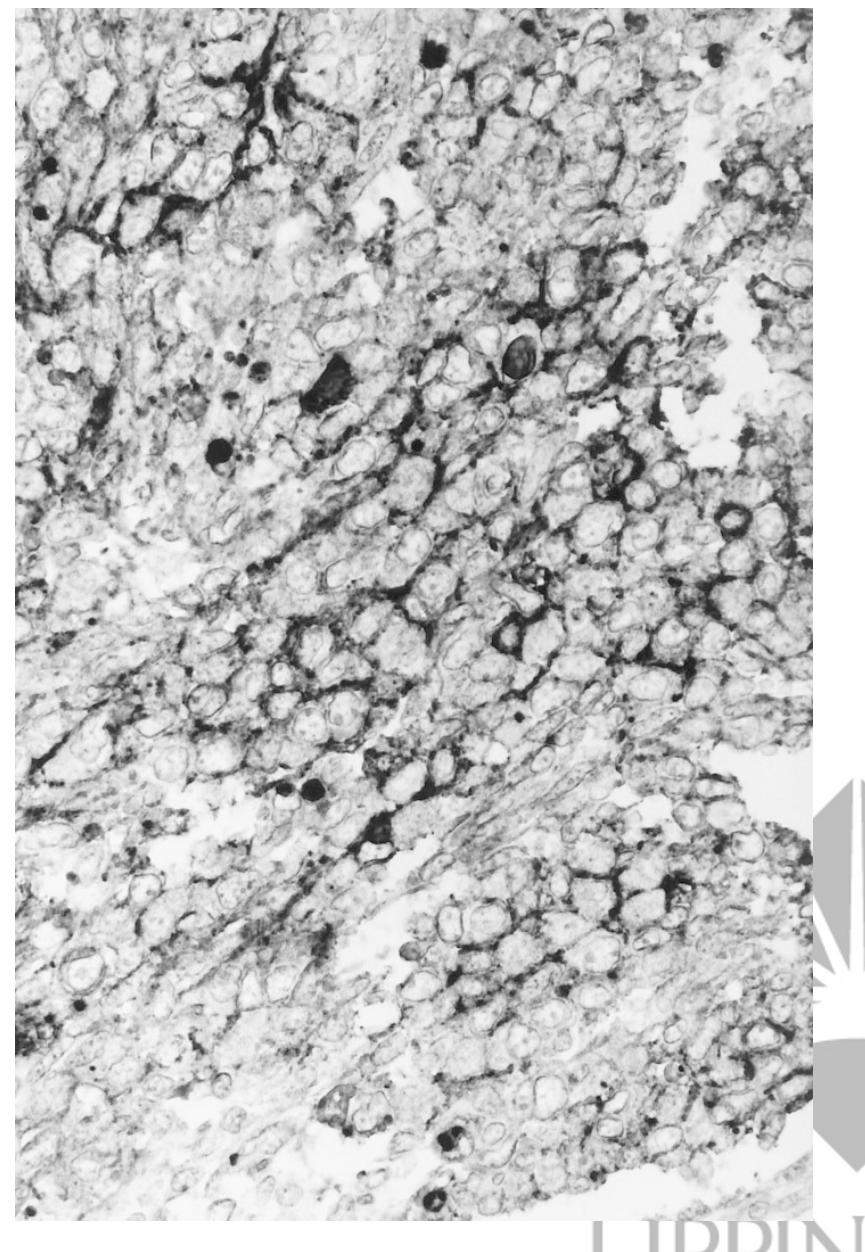

FIGURE 2. Malignant müllerian mixed tumor, showing distinct cytoplasmic staining for CD10 in the sarcomatous components.

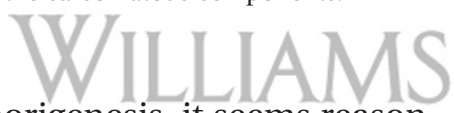

From the view of tumorigenesis, it seems reasonable that the sarcomatous component in MMMTs and adenosarcoma, both of which are müllerian derived, show differentiation into the endometrial stroma as represented by CD10 expression. Interestingly, one high-grade endometrial sarcoma in our series, predominantly involving the endometrium and inner half of the myometrium, showed immunoreactivity for CD10, which suggests a possible endometrial stromal origin, although in the current view the use of the term high-grade endometrial stromal sarcoma is not preferred to designate such a tumor because of absence of distinct evidence of stromal differentiation in the literature (29-31).

In general, MMMT can be distinguished from low-grade ESS by high-grade morphology of the sarcomatous component, occasional heterologous components such as cartilage or striated muscle, and the coexistence of malignant epithelial components, which can be serous, endometrioid, mucinous, and/or squamous cell carcinoma, whereas adenosarcoma is distinguished by a mixture of benign-looking müllerian-type epithelium and sarcomatous components. In MMMTs and adenosarcoma, however, sarcomatous components can be prominent and may vary in degree of atypia, ranging from low-grade to high-grade, both of which can be CD10 positive. Therefore, in cases in which only limited sampling has been possible, the distinction between these tumors could be difficult, and in such situations immunohistochemistry for CD10 expression might be misleading.

Other notable findings are the existence of CD10positive carcinomatous components and rhabdomyoblastic cells in MMMTs. Occasionally both CD10 and keratin-positive spindle cells in sarcomatous components and CD10-positive carcinomatous components link epithelial and nonepithelial components in the histogenesis of MMMT. The origin of MMMT has been a controversial issue, but some investigators favor an epithelial nature of the tumor based on the observation that its biologic behavior is closer to endometrial carcinoma rather than true sarcoma $(32,33)$ and that both tumors are

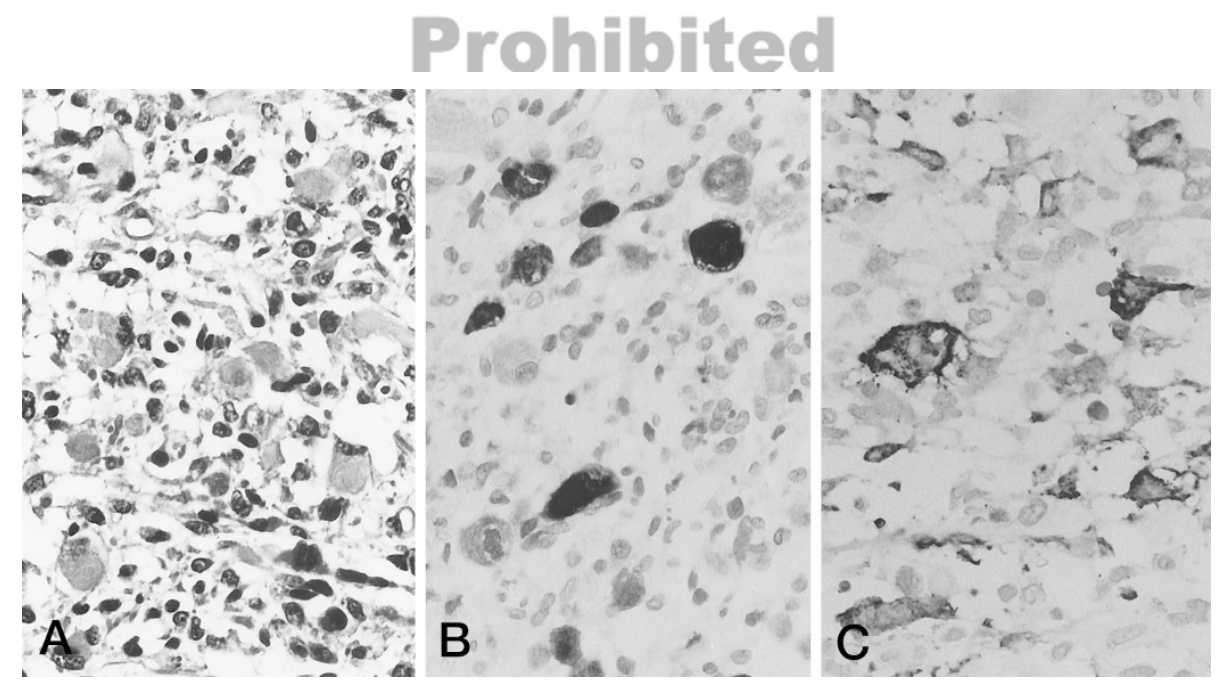

FIGURE 3. Rhabdomyoblastic cells in malignant müllerian mixed tumor, with abundant eosinophilic and filamentous cytoplasm scattered in the sarcomatous components (A), which are positive for myoglobin (B) and CD10 (C). 


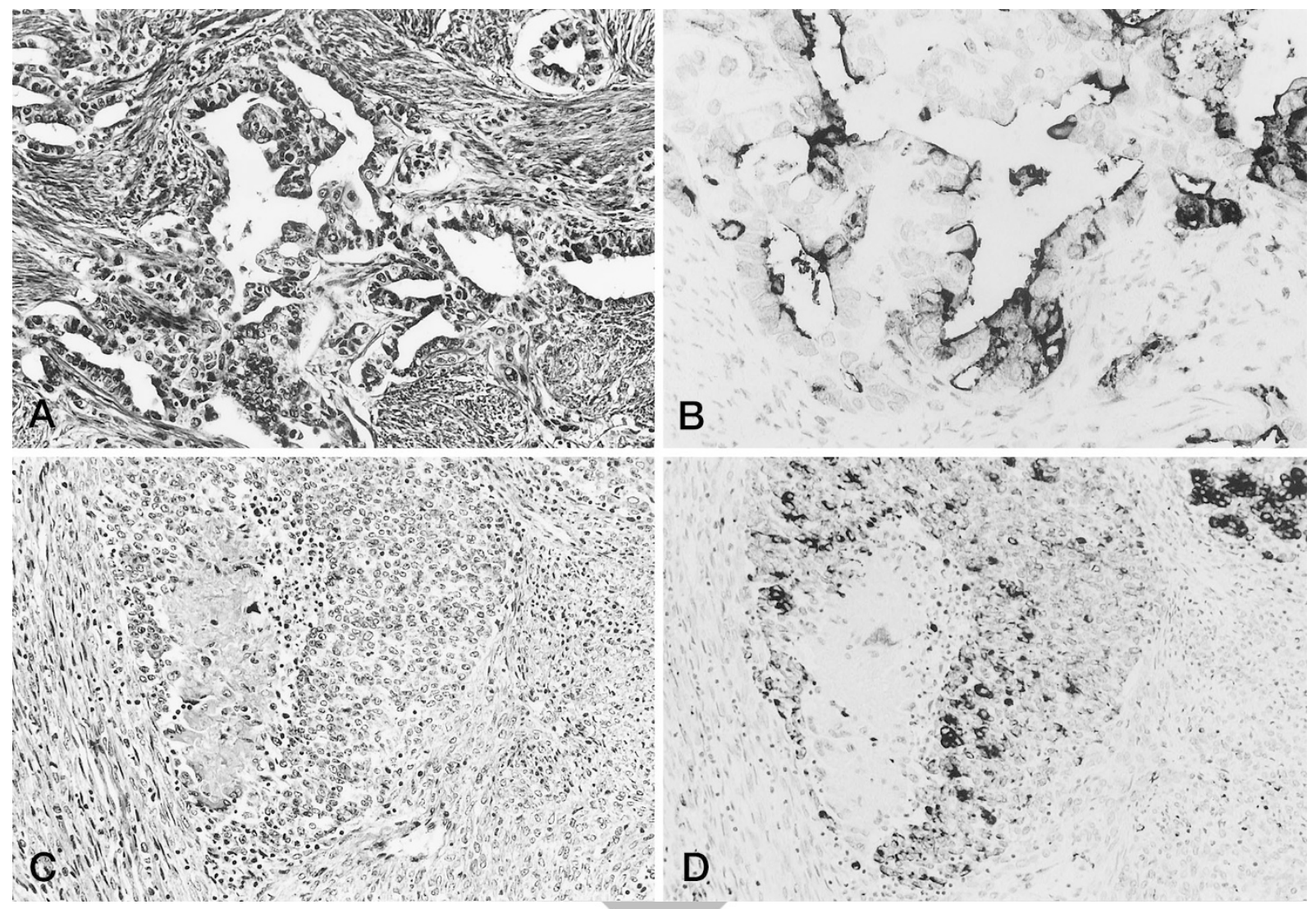

FIGURE 4. Carcinomatous components in malignant müllerian mixed tumor. Elements of adenocarcinoma (A) show membranous and cytoplasmic staining for CD10 (B). Portions of undifferentiated carcinoma (C) also contain cells positive for CD10 (D).

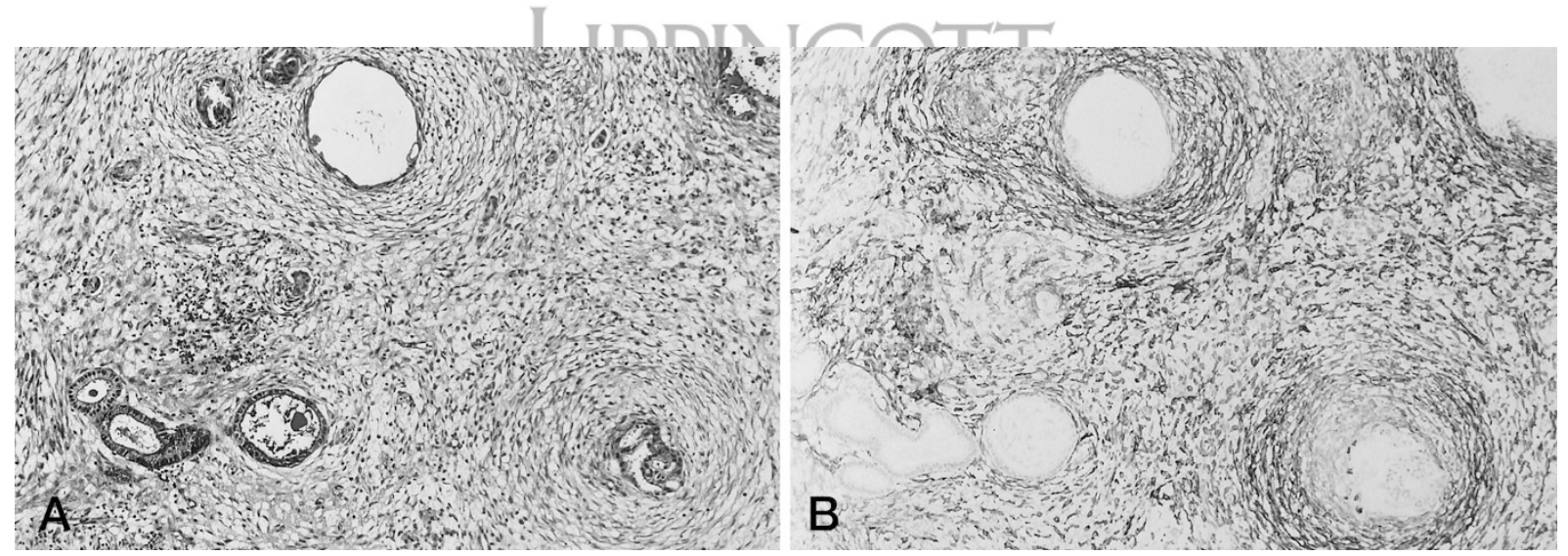

FIGURE 5. Müllerian adenosarcoma, characterized by a mixture of benign-appearing müllerian-type epithelium and sarcomatous components consisting of spindle-shaped cells (A). Hypercellular areas accentuated by strong CD10 expression are arranged in a concentric fashion around dilated glands (B).

related to the same etiologic factors (34). Therefore, it seems possible that the CD10-positive sarcomatous component is a derivative of CD10-positive epithelial components through the process of mesenchymal metaplasia. Another explanation is that epithelial and nonepithelial components originate from common stem cells independently. Nevertheless, the significance of CD10 expression in both epithelial and nonepithelial components remains to be defined.
Myoglobin- and/or desmin-positive rhabdomyoblastic cells with abundant eosinophilic and filamentous cytoplasm in MMMTs and adenosarcomas were consistently CD10 positive, as they were in the one primary uterine rhabdomyosarcoma. Chu and Arber (8) demonstrated that $3(60 \%)$ of 5 extrauterine rhabdomyosarcomas were also positive for CD10, suggesting CD10 expression is not restricted to rhabdomyoblastic cells in uterine tumors. On the other hand, the intimate relationship 
TABLE 2. Summary of Immunohistochemical Findings

\begin{tabular}{|c|c|c|c|c|c|c|c|c|c|}
\hline Case & Diagnosis & Age (y) & Site & CD10 & Myoglobin & $\alpha$-SMA & Desmin & CAM5.2 & Remarks \\
\hline 1 & MMMT, heterologous & 65 & Uterine corpus & ++ & ++ & + & ++ & Epi & $\begin{array}{l}\text { CD10-positive rhabdomyoblastic } \\
\text { cells identified }\end{array}$ \\
\hline 2 & MMMT, heterologous & 57 & Uterine corpus & ++ & ++ & + & ++ & Epi & $\begin{array}{l}\text { CD10-positive rhabdomyoblastic } \\
\text { cells identified }\end{array}$ \\
\hline 3 & MMMT, heterologous & 65 & Uterine corpus & +++ & + & +++ & - & Epi & \\
\hline 4 & MMMT, heterologous & 69 & Uterine corpus & +++ & - & +++ & - & Epi/Sarc (focal) & \\
\hline 5 & MMMT, heterologous & 58 & Uterine corpus & +++ & - & ++ & - & Epi & \\
\hline 6 & MMMT, heterologous & 59 & Uterine cervix & + & - & + & - & Epi & \\
\hline 7 & MMMT, heterologous & NA & Tube & +++ & + & - & + & Epi & $\begin{array}{l}\text { CD10-positive rhabdomyoblastic } \\
\text { cells identified }\end{array}$ \\
\hline 8 & MMMT, heterologous & NA & Tube & +++ & - & + & - & Epi & \\
\hline 9 & $\begin{array}{l}\text { MMMT, heterologous } \\
\text { (metastasis) }\end{array}$ & 59 & Abdomen & ++ & - & - & + & Epi & \\
\hline 10 & MMMT, heterologous & 69 & Uterine corpus & ++ & + & + & - & Epi & $\begin{array}{l}\text { CD10-positive rhabdomyoblastic } \\
\text { cells identified }\end{array}$ \\
\hline 11 & MMMT, heterologous & 69 & Uterine corpus & +++ & - & - & - & Еp & \\
\hline 12 & MMMT, homologous & 56 & Uterine corpus & ++ & - & - & - & Epi/Sarc (focal) & \\
\hline 13 & ESS, low grade & 45 & Uterine corpus & +++ & - & - & - & - & \\
\hline 14 & ESS, low grade & NA & Uterine corpus & +++ & - & + & - & focal & \\
\hline 15 & $\begin{array}{l}\text { High-grade endometrial } \\
\text { sarcoma }\end{array}$ & 45 & Uterine corpus & ++ & - & - & - & - & \\
\hline 16 & $\begin{array}{l}\text { Adenosarcoma, with } \\
\text { stromal overgrowth }\end{array}$ & 64 & Uterine corpus & ++ & & + & ++ & Epi & $\begin{array}{l}\text { CD10-positive rhabdomyoblastic } \\
\text { cells identified }\end{array}$ \\
\hline 17 & Adenosarcoma & 53 & Uterine corpus & & & & ++ & Epi & $\begin{array}{l}\text { CD10-positive rhabdomyoblastic } \\
\text { cells identified }\end{array}$ \\
\hline 18 & Adenosarcoma & 41 & Uterine corpus & & ND & NI & ND & ND & \\
\hline 19 & Adenosarcoma & 26 & Uterine cervix & & & & & Epi/Sarc (focal) & $\begin{array}{l}\text { CD10-positive rhabdomyoblastic } \\
\text { cells identified }\end{array}$ \\
\hline 20 & Adenosarcoma & 33 & Uterine cervix & & ND & ND & ND & ND & \\
\hline 21 & Adenosarcoma & 46 & Tube & & ND & & ND & ND & \\
\hline 22 & $\begin{array}{l}\text { Leiomyosarcoma, high } \\
\text { grade }\end{array}$ & 42 & Uterine corpus & & $\mathrm{ND}$ & & + & ND & \\
\hline 23 & $\begin{array}{l}\text { Leiomyosarcoma, high } \\
\text { grade }\end{array}$ & 52 & Uterine corpus & +++ & & & + & ND & \\
\hline 24 & Rhabdomyosarcoma & 23 & Uterine cervix & ++ & ++ & ND & ++ & ND & \\
\hline 25 & Rhabdomyosarcoma & 62 & Uterine corpus & & & & ++ & Sarc & $\begin{array}{l}\text { CD10-positive rhabdomyoblastic } \\
\text { cells identified }\end{array}$ \\
\hline
\end{tabular}

MMMT, malignant müllerian mixed tumor; ESS, endometrial stromal sarcoma; SMA, smooth muscle actin;,$+++>50 \%$ tumor cells with positive immunoreactivity;,$++ 10-50 \%$ tumor cells with positive immunoreactivity;,$+<10 \%$ of cells with positive immunoreactivity; - , negative; Epi, positive in epithelial component; Sarc, positive in sarcomatous component; NA, not available; ND, not donē.

between endometrial stroma and skeletal muscle differentiation is suggested by the rare examples of stromal nodule with skeletal muscle differentiation (35), ESS with rhabdoid differentiation (36), and adenomyofibroma with skeletal muscle differentiation (37). Therefore, CD10 expression might be a common phenotypic characteristic suggesting müllerian derivation of rhabdomyoblastic cells, although this subject requires further studies and assessment.

In our series, high-grade leiomyosarcomas showed distinct and extensive immunoreactivity for

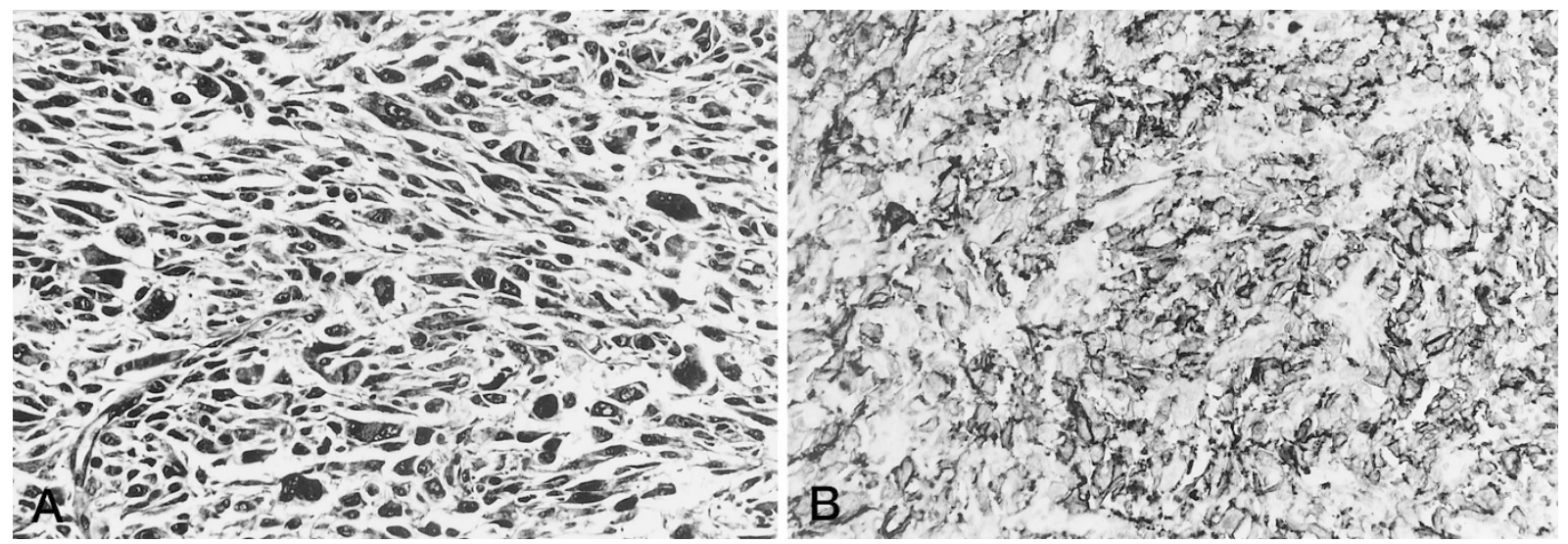

FIGURE 6. High-grade leiomyosarcoma characterized by pleomorphic nuclear morphology and increased mitotic figures (A). Neoplastic cells show cytoplasmic immunoreactivity for CD10 (B) 
CD10 in areas. Recent studies have also shown that a small population of leiomyoma and leiomyosarcoma are focally positive for CD10 (20-22). Although CD10 expression in smooth muscle tumors seems an uncommon event, high-grade leiomyosarcomas still need to be examined because our data suggest that CD10 expression is not contributory in distinguishing between ESS and high-grade leiomyosarcoma. The significance of CD10 expression in smooth muscle tumors also remains unclear, but it is possible that CD10 expression represents true endometrial stromal differentiation.

In summary, the current study has disclosed that the sarcomatous components of MMMTs as well as adenosarcoma are almost always positive for CD10. In addition, high-grade endometrial sarcoma and leiomyosarcoma can also be positive. Therefore, distinction between these tumors should rely on a constellation of morphologic features combined with CD10 immunohistochemistry. CD10 expression might be a common immunophenotypic characteristic of neoplastic mesenchymal cells of müllerian origin, which is shared by ESS, MMMT, adenosarcoma, rhabdomyosarcoma, and leiomyosarcoma. The significance of CD10 expression still needs to be pursued by further studies.

Acknowledgments: We thank Dr. Yasuo Nakata at Hyogo Medical School Hospital, Dr. Yasumasa Monobe at Kawasaki Hospital, Okayama, and the Laboratory of Pathology, Tokyo Health Service Association, Tokyo, Japan for contributing a portion of the materials for the current study.

\section{REFERENCES}

1. Greaves MF, Hariri G, Newman RA, Sutherland DR, Ritter MA, Ritz J. Selective expression of the common acute lymphoblastic leukemia (gp 100) antigen on immature lymphoid cells and their malignant counterparts. Blood 1983;61:62839 .

2. Weiss LM, Bindl JM, Picozzi VJ, Link MP, Warnke RA. Lymphoblastic lymphoma: an immunophenotype study of 26 cases with comparison to $\mathrm{T}$ cell acute lymphoblastic leukemia. Blood 1986;67:474-8.

3. Gregory CD, Tursz T, Edwards CF, Tetaud C, Talbot M, Caillou B, et al. Identification of a subset of normal B cells with a Burkitt's lymphoma (BL)-like phenotype. J Immunol 1987;139:313-8.

4. Stein H, Lennert K, Feller AC, Mason DY. Immunohistological analysis of human lymphoma: correlation of histological and immunological categories. Adv Cancer Res 1984;42:67147.

5. Holm-Nielsen P, Pallesen G. Expression of segment-specific antigens in the human nephron and in renal epithelial tumors. APMIS Suppl 1988;4:48-55.

6. Droz D, Zachar D, Charbit L, Gogusev J, Chretein Y, Iris L. Expression of the human nephron differentiation molecules in renal cell carcinomas. Am J Pathol 1990;137:895-905.

7. Avery AK, Beckstead J, Renshaw AA, Corless CL. Use of antibodies to RCC and CD10 in the differential diagnosis of renal neoplasms. Am J Surg Pathol 2000;24:203-10.
8. Chu P, Arber DA. Paraffin-section detection of CD10 in 505 nonhematopoietic neoplasms. Frequent expression in renal cell carcinoma and endometrial stromal sarcoma. Am J Clin Pathol 2000;113:374-82.

9. Dragovic T, Sekosan M, Becker RP, Erdos EG. Detection of neutral endopeptidase 24.11 (neprilysin) in human hepatocellular carcinomas by immunocytochemistry. Anticancer Res 1997;17:3233-8.

10. Xiao SY, Wang HL, Hart J, Fleming D, Beard MR. cDNA arrays and immunohistochemistry identification of CD10/ CALLA expression in hepatocellular carcinoma. Am J Pathol 2001;159(4):1415-21.

11. Sato Y, Itoh F, Hinoda Y, Ohe Y, Nakagawa N, Ueda R, et al. Expression of CD10/neutral endopeptidase in normal and malignant tissues of the human stomach and colon. J Gastroenterol 1996;31:12-7.

12. Notohara K, Hamazaki S, Tsukayama C, Nakamoto S, Kawabata K, Mizobuchi K, et al. Solid-pseudopapillary tumor of the pancreas: immunohistochemical localization of neuroendocrine markers and CD10. Am J Surg Pathol 2000;24: 1361-71.

13. Satoh F, Tsutsumi Y, Yokoyama S, Osamura RY. Comparative immunohistochemical analysis of developing kidneys, nephroblastomas and related tumors: considerations on their histogenesis. Pathol Int 2000;50:458-71.

14. Carrel S, de Tribolet N, Gross N. Expression of HLA-DR and common acute lymphoblastic leukemia antigens on glioma cells. Eur J Immunol 1982;12:354-7.

15. Monod L, Hamou MF, Ronco P, Verroust P, de Tribolet N. Expression of cALLa/NEP on gliomas: a possible marker of malignancy. Acta Neurochir (Wien) 1992;114:3-7.

16. Brox AG, Lavallee MC, Arseneau J, Langleben A, Major PP. Expression of common acute lymphoblastic leukemiaassociated antigen on germ cell tumor. Am J Med 1986;80: $1249-52$.

17. Kanitakis J, Bourchany D, Claudy A. Expression of the CD10 antigen (neutral endopeptidase) by mesenchymal tumors of the skin. Anticancer Res 2000;20:3539-44.

18. Imai K, Kanzaki H, Fujiw̌ara H, Kariya M, Okamoto N, Takakura K, et al. Expression of aminopeptidase $\mathrm{N}$ and neutral endopeptidase on the endometrial stromal cells in endometriosis and adenomyosis. Hum Reprod 1992;7:1326-8.

19. Imai K, Maeda M, Fujiwara H, Okamoto N, Kariya M, Emi N, et al. Human endometrial stromal cells and decidual cells express cluster of differentiation (CD) 13 antigen/aminopeptidase $\mathrm{N}$ and $\mathrm{CD} 10$ antigen/neutral endopeptidase. Biol Reprod 1992;46:328-34.

20. Chu PG, Arber DA, Weiss LM, Chang KL. Utility of CD10 in distinguishing between endometrial stromal sarcoma and uterine smooth muscle tumors: an immunohistochemical comparison of 34 cases. Mod Pathol 2001;14:465-71.

21. Agoff SN, Grieco VS, Garcia R, Gown AM. Immunohistochemical distinction of endometrial stromal sarcoma and cellular leiomyoma. Appl Immunohistochem Mol Morphol 2001;9:164-9.

22. McCluggage WG, Sumathi VP, Maxwell P. CD10 is a sensitive and diagnostically useful immunohistochemical marker of normal endometrial stroma and of endometrial stromal neoplasms. Histopathology 2001;39:273-8.

23. Toki T, Shimizu M, Takagi Y, Ashida T, Konishi I. CD10 is a marker for normal and neoplastic endometrial stromal cells. Int J Gynecol Pathol 2002;21:41-7.

24. Franquemont DW, Frierson HF Jr, Mills SE. An immunohistochemical study of normal endometrial stroma and endometrial stromal neoplasms. Evidence for smooth muscle differentiation. Am J Surg Pathol 1991;15:861-70.

25. Lillemoe TJ, Perrone T, Norris HJ, Dehner LP. Myogenous phenotype of epithelial-like areas in endometrial stromal sarcomas. Arch Pathol Lab Med 1991;115:215-9. 
26. Farhood AI, Abrams J. Immunohistochemistry of endometrial stromal sarcoma. Hum Pathol 1991;22:224-30.

27. Nucci MR, O'Connell JT, Huettner PC, Cviko A, Sun D, Quade BJ. h-Caldesmon expression effectively distinguishes endometrial stromal tumors from uterine smooth muscle tumors. Am J Surg Pathol 2001;25:455-63.

28. Rush DS, Tan J, Baergen RN, Soslow RA. h-Caldesmon, a novel smooth muscle-specific antibody, distinguishes between cellular leiomyoma and endometrial stromal sarcoma. Am J Surg Pathol 2001;25:253-8.

29. Evans HL. Endometrial stromal sarcoma and poorly differentiated endometrial sarcoma. Cancer 1982;50:2170-82.

30. Chang KL, Crabtree GS, Lim-Tan SK, Kempson RL, Hendrickson MR. Primary uterine endometrial stromal neoplasms. A clinicopathologic study of 117 cases. Am J Surg Pathol 1990;14:415-38.

31. Kempson RL, Hendrickson MR. Smooth muscle, endometrial stromal, and mixed Mullerian tumors of the uterus. Mod Pathol 2000;13:328-42.

32. Silverberg SG, Major FJ, Blessing JA, Fetter B, Askin FB, Liao SY, et al. Carcinosarcoma (malignant mixed meso- dermal tumor) of the uterus. A Gynecologic Oncology Group pathologic study of 203 cases. Int J Gynecol Pathol 1990;9:1-19.

33. Bitterman P, Chun B, Kurman RJ. The significance of epithelial differentiation in mixed mesodermal tumors of the uterus. A clinicopathologic and immunohistochemical study. Am J Surg Pathol 1990;14:317-28.

34. Zelmanowicz A, Hildesheim A, Sherman ME, Sturgeon SR, Kurman RJ, Barrett RJ, et al. Evidence for a common etiology for endometrial carcinomas and malignant mixed mullerian tumors. Gynecol Oncol 1998;69:253-7.

35. Lloreta J, Prat J. Endometrial stromal nodule with smooth and skeletal muscle components simulating stromal sarcoma. Int J Gynecol Pathol 1992;11:293-8.

36. Kim YH, Cho H, Kyeom-Kim H, Kim I. Uterine endometrial stromal sarcoma with rhabdoid and smooth muscle differentiation. J Korean Med Sci 1996;11:88-93.

37. Sinkre P, Miller DS, Milchgrub S, Hameed A. Adenomyofibroma of the endometrium with skeletal muscle differentiation. Int J Gynecol Pathol 2000;19:280-3.

\section{Book Review}

\section{Brown TA: Genomes. 2nd Edition, 520 pp, New York, Wiley-Liss, in arrangement with Bios Scientific Publishers, Oxford, UK, 2002 (\$97.50).}

Intrigued by the physical beauty of this book, I opened it to find out how much is expected from today's biology majors. Then I persuaded myself to continue, if for no other reason than to find out how much behind I am in molecular biology. Now, after a minicourse based on this didactic masterpiece prepared by professor Brown of Manchester, UK, I feel almost glum that nobody will ever ask me about transcriptomes and proteomes.

While summarizing my impressions about this text, the first question that came to my mind was: Is the present book so exciting because it deals with a discipline that is advancing so rapidly, or is it the frontiersmen spirit of the key players (captured masterfully by the author) that is so infectious? There is no doubt that molecular biology has attracted the smartest of the smartest biomedical scientists and that the discoveries that these men and women have made are stultifying. But it is also important to note that books like this one are an important vehicle for transmitting the enthusiasm to the uninitiated and for attracting new investigators. Could one ever write such an exciting textbook of pathology?
The second edition appears only 3 years after the critically acclaimed first edition. The book is divided into four parts dealing, among others, with physical and biochemical properties of the genome, methods used for studying gene expression, mapping genes and sequencing them, accessing the genome, protein synthesis and regulating gene activity, and applying these techniques to the study of gene replication and phylogenetics. In the new layout each chapter begins with a list of 'learning outcomes' (according to the author 'an innovation forced on UK universities by the quality-assessment initiatives') and ends with references for further reading, study aids (lists of key words), and questions for problem-based learning. Color diagrams and conceptual illustrations and boxed texts on technical details of true experiments (titled 'research briefings') are additional features that make this book extremely user friendly. At the end of the book there is a glossary of most important terms.

This model of a modern university textbook deserves to be read and studied by undergraduate as well as graduate biomedical students worldwide.
Ivan Damjanov
University of Kansas School of Medicine
Kansas City, Kansas 